\title{
An Innovative Prototype Model of Management to Confront with Coronavirus Disease 2019 (COVID-19): A Case Study of Mahachulalongkornrajavidyalaya University
}

\author{
Phra Theppavaramethi ${ }^{1}$, Lampong Klomkul $^{2}$, Yasumin Inkrungkao ${ }^{3}$ \\ ${ }^{1,2,3}$ Mahachulalongkornrajavidyalaya University, Thailand \\ 1 paramethi.59@gmail.com, ${ }^{2}$ research.mcu@gmail.com,3boom.mcu@gmail.com, \\ ${ }^{2}$ research.mcu@gmail.com
}

\begin{abstract}
The purposes of this research article were 1) to analyze crises situation and measures to prevent the epidemic of Coronavirus 2019 (COVID-19), 2) to conduct lessons learned on management of the Coronavirus Outbreak situation 2019 (COVID-19) of Mahachulalongkornrajavidyalaya University (MCU), and 3) to propose an innovative prototype model of management to confront with Coronavirus epidemic situation (COVID19) of MCU. Action research was conducted as it was a research method that suitable for urgent situations where action must be taken to resolve problems promptly. Target groups were personnel and students of MCU who work or live in the area of MCU. The research tools were interview question guidelines, issues in group interviews, and field record. Qualitative data analysis using content analysis and analytic in duction was conducted. Results indicated that 1) the outbreak of the coronavirus 2019 affects the university administration that was unable to operate normally. For disease prevention measures, five measures were established consisted of 1) measures for the performance of university personnel; 2) measures for educational management; 3) measures for staff and students living in university; 4) measures for public communication; and 5) a measure of internal management within the university area. All five measures will be carried out with the university's center for the control and prevention of the epidemic of COVID 19. 2) The sixth prototype was being conducted from lessons learned on management of the coronavirus epidemic situation (COVID-19) of MCU. 3) An innovative prototype model of Seven ways of New Normal Confronting with COVID-19, there are 7 ways consisted of 1) method of new normal life focusing on health care, 2) method of new normal working using online communication, 3) method of new normal teaching and instruction using online blended learning, 4) method of new normal research and academic management focusing on online working, 5) method of Dhamma public communication in new normal focusing on social distancing, 6) method of sharing expression in new normal using sharing pantries, and 7) method of coexistence in university following Buddhist New Normal
\end{abstract}

\section{Index Terms}

Innovative Prototype Model, Coronavirus Disease 2019, Mahachulalongkornrajavidyalaya University

Article Received: 10 August 2020, Revised: 25 October 2020, Accepted: 18 November 2020

\section{Introduction}

From the situation of the coronavirus outbreak 2019 has spread all over the world with information on 31 December 2019 in Wuhan People's Republic of China Outbreaks of atypical pneumonia caused by Coronavirus 2019 (2019$\mathrm{nCoV}$ ) that have spread from other Chinese cities have been reported and have spread worldwide. As it appears in the current situation subsequently, data as of March 28, 2010 found that the number of infected worldwide was 597,267 people and the United States had the highest number of cases at 104,126 , followed by Italy, which had more cases than China. Later it was Spain, Germany, France, Iran, England and Switzerland. This shows that the effects of the epidemic in Europe are becoming more widespread. For Thailand according to Dr. Taweesil Wissanuyothin, a spokesman for the Coronavirus Outbreak Management Center 2019, reports of the COVID-19 epidemic situation in Thailand found that at the end of the month there were the number of people infected in March 2020 has continued to rise. (Matichon Online: 29 March 2020) and on March 30, 2010, there were 136 new cases of infection with the cumulative total 1,524 people, according to information that the situation of the virus outbreak still does not stop and continued to increase the number of patient statistics. From the phenomenon of each country as daily news, there is research that created a body of knowledge about methods to measure performance. In preventing the spread of the 2019 coronavirus, it is useful to monitor and take lessons learned from the experience of different areas.

This is as evidenced in the Shan-Lu Liu and Linda Saif (2020) [1] study on Emerging Viruses without Borders: The Wuhan Coronavirus, reflecting the findings of the study. The new coronavirus in Wuhan, China, claimed at least two lives as of January 17, 2010 and infected hundreds. The situation has attracted international attention, including the virology community. Rapid publicity of new virus genome sequences by Chinese virologists, but it also believes that increased transparency in disease reporting and sharing of information with international colleagues is critical for controlling the world's spread of the virus.

A study in Peng Shao's research (2020) [2] on "Impact of city and residential unit lockdowns on prevention and control of COVID-19)" found that managed studies yielding results on the implementation of measures to closing cities leads to higher mortality in these cities due to reduced mobility. Moreover, the use of closed-town systems, along with the addition of hospital beds, improved treatment and reduced mortality, strict operations and premature closure of residential apartments. This makes it more effective in controlling the spread of disease and reducing the number of hospital beds. In general, measures should be taken to shut down cities and homes to prevent the spread of COVID-19. In addition, medical resources should be increased in closed 
cities. These measures will help reduce the spread of the virus to other cities and provide appropriate treatment for the sick in the city under that city closure. It also included in the work of the European Center for Disease Prevention and Control (2020) Novel coronavirus disease 2019 ( COVID19) pandemic: increased transmission in the EU / EEA and the UK [3].

As well as in research by Shulin Liu, Zhi-gang Wang (Nankai University), Hai-Yan Xie, An-An Liu (2020) [4] on Single-Virus Tracking: From Imaging Methodologies to Virological Applications, and work by Hui Luo, Qiao. -ling Tang, Ya-xi Shang, Jian-Ping Liu (2020) [5] in Can Chinese Medicine Be Used for Prevention of Corona Virus Disease 2019 ( COVID-19)? A Review of Historical Classics, Research Evidence and Current Prevention Programs pictured include this research that reflects the state of the results of surveillance studies on viral distribution in China, Italy and the United States including acquiring knowledge as a preventive measure. Modeling is the knowledge of virus fragmentation and prevention measures. All of which are real snapshots of the world community today.

At the national level, the Prime Minister has announced a declaration of state of emergency according to the Royal Decree on Public Administration in Emergency Situations, 2015 as published in the Government Gazette, Volume 33, Part 24 A, dated March 25, 2020, referring to the Cabinet's approval. At the meeting on 24 March 2020 and with the advice of administrators and academics of medicine and public health under the authority under Section 5 of the Royal Decree of Public Administration in Emergency Situation B.E. 2554 announces the state of emergency in all areas throughout the Kingdom. From March 26, 2020 to April 30, 2020, the announcement of the state of emergency is in accordance with the laws that have been established since B.E. 2558, since the situation has now spread. The outbreak of Coronavirus 2019 ( COVID-19), a newly emerging pandemic, has spread rapidly around the world and Thailand has been affected as well.

At this time, there is no effective vaccine and treatment for this. Therefore, the government has taken measures to prevent, block, delay and build people's awareness and understanding on a daily basis. According to the progress of the situation information and the medical advice of all specialists by taking into account the impact on people in terms of social and living, living economy, state resources, public health and the prevention of excessive panic. It is extremely dangerous because it will affect the efficiency of the medical services and the use of public health resources of the country.

All parties agreed that the situation should be raised to the maximum enforcement of measures, so that the state can bring more measures to take effect from the original as for which measures to choose first. There will be further announcements and requirements to be announced, but initially it was necessary to declare a state of emergency first which has been announced now and the result of the announcement is that the government will have a channel under the law to control or manage any situation, for example, some powers of the Minister will be transferred. According to some laws, the Prime Minister is necessary and temporarily for speed and integration. A requirement will be issued certain prohibitions or practices such as prohibiting entering and exiting certain places prohibit or restrict entry and exit to the Kingdom and the movement of large numbers of people across the area. Control of the use of vehicles, traffic routes, control of goods and medical supplies. These measures even in accordance with the law on public administration in emergency situations and even if the situation from the numbers Number of people infected and death in the country.

The government has asked people to trust in the country's public health system and please take care of your health himself because of having no disease is truly a great fortune. At the same time, please cooperate with the authorities in order to strictly adhere to medical measures and advice as well as receive information Published through official channels such as radio, television, print media with a reliable reference source. It is not a rumor or news that has no known sources. If in doubt, ask the Ministry of Public Health, or, the COVID-19 epidemic situation management center (COVID-19), staying at home according to the saying "stay at home, stop infecting for the nation". A lot taking preventive measures for oneself and showing social responsibility such as using masks, hand sanitizer, not touching or receiving the infection with saliva spray, keeping social distancing from others, visiting a doctor in case of suspicion. It is accepted all over the world that we can reduce our risks as best as we can to protect ourselves, our relatives and the society.

As a result of the above measures, other mechanisms spread throughout the country, including Mahachulalongkornrajavidyalaya University has set guidelines management guidelines in the current situation, the Most Venerable Prof. Dr. Phra Rajapariyatkavi, on the Rector met the MCU community, on March 26, 2020, which is significant due to the current situation of the coronavirus epidemic. There was a meeting with the Vice-retors of the Central Campus, the Dean and the Director of the Central College of Education established guidelines to prevent the spread of COVID-19 on March 18, 2020. The main seven main issues are (1) measures for student administration, education, teaching, evaluation, evaluation, both central and regional. Educational management services, teaching, evaluation, educational evaluation by using the online system mainly. The central exam course has changed the schedule of examinations from the original using the format of an exam by the online exam method, and there is a schedule for the exam. More information can be found at the Registration and Evaluation Office; (2) the work of personnel is an administration to support education both the central and regional parts are classified as (a) the type of work that can work at home by working online, (b) the one that must work at the office, the administers should consider and establish a time-lapse working model for the office attendant to take turns to adhere to the social distance process, which is the social distance in accordance with the government's policy, (3) building management to the central and region. There is a spray of disinfectant fluid which would like the senior management in the region, even as the monastic college campus, to study on finding disinfectant to inject sterilization. Set and limit access to the university area to have a screening point, fever measure, take care of orderliness, one-way entry to supervise and tighten up. (4) The organization of various project activities of the 
university refrain from activities that involve large groups of people, no summer ordination and training projects, no other activities normally performed by the university year, so that we don't have to come together in many groups or operated in an online format. (5) Central or regional nutrition have students living in the university area who cannot travel back to their own countries. The university therefore has to take care of nutrition which has been managed either me in a private container, social distancing and using alcohol gel. (6) Establishing a center for the control and prevention of the spread of COVID-19 in Central Wang Noi has set up a separate center to prevent the spread of COVID-19. Because it is a large center and there are a lot of people going in and out each day. Therefore, a center for the control and prevention of the epidemic of COVID-19 has been set up, a dedicated office has a 24-hour center staff. Information is gathered from both inside and outside, screening inspection for senior management. In the region, vice-rector for regional campus Director of Sangha College has studied the operational duties of the location supervision center. In the center to consider actions in the responsible region to prevent the spread of the COVID-19. (7) For graduation ceremony, the graduation ceremony has been postponed until it is in the normal state. A proposal for a degree approval is presented to the Dean, President and Chairman of the University Council Signing a diploma, and other evidence showing that the student has completed a Bachelor Degree, Master degree, and Doctoral Degree. It will be according to the calendar that has been made the degree and qualifications in all respects have the right to use the degree as desired in all respects.

In addition, the Center for the Control and Prevention of the Epidemic of COVID-19, Mahachulalongkorn rajavidyalaya Central University, is presided over by Associate Professor Dr. Phra Theppavaramethi. Therefore, there should be research to study and conduct the lessons learned results of that operation by studying an innovative prototype model of management to confront with Coronavirus Disease 2019 (COVID-19): A case study of Mahachulalongkornrajavidyalaya University in order to study the guidelines or follow up the mechanism for implementing the university's guidelines and measures, both in terms of situations measures established and implemented by the university as well as to conduct the body of knowledge on guidelines and measures to be used as a knowledge from lessons learned for prevention, and to put in place and monitor measures for further action.

\section{Research Objectives}

The purposes of this research article were 1) to analyze crises situation and measures to prevent the epidemic of Coronavirus 2019 (COVID-19), 2) to conduct lessons learned on management of the Coronavirus Outbreak situation 2019 (COVID-19) of Mahachulalongkornrajavidyalaya University (MCU), and 3) to propose an innovative prototype model of management to confront with Coronavirus epidemic situation (COVID-19) of MCU.

\section{Conceptual Framework}

An Innovative Prototype Model of Management to Confront with Coronavirus Disease 2019 (COVID-19): A Case Study of Mahachulalongkornrajavidyalaya University was an urgent research that conducted during COVID-19 pandemic. Conceptual framework was set as in Fig.1.

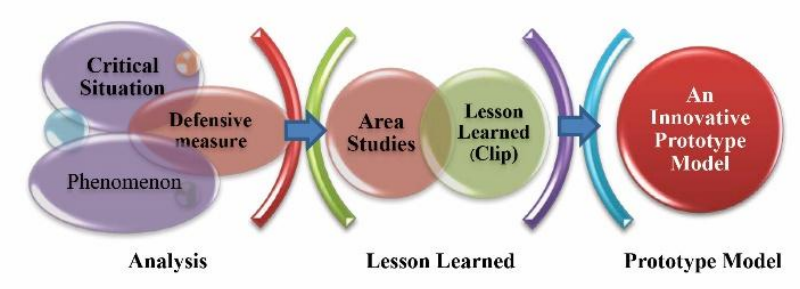

Fig.1 Conceptual Framework

\section{Research Methods}

The research design for this research was based on the Action Research design, as it is a research method suitable for urgent situations where action must be taken to resolve problems promptly. The research process is divided into 4 important steps: Step 1 Planning (Plan), Step 2 Action (Act), Step 3 Observe, and Step 4 Reflect the results (Reflect) or called PAOR process. For this research, the Action Research Design Model for Lesson learned was designed for lesson learned as follows.

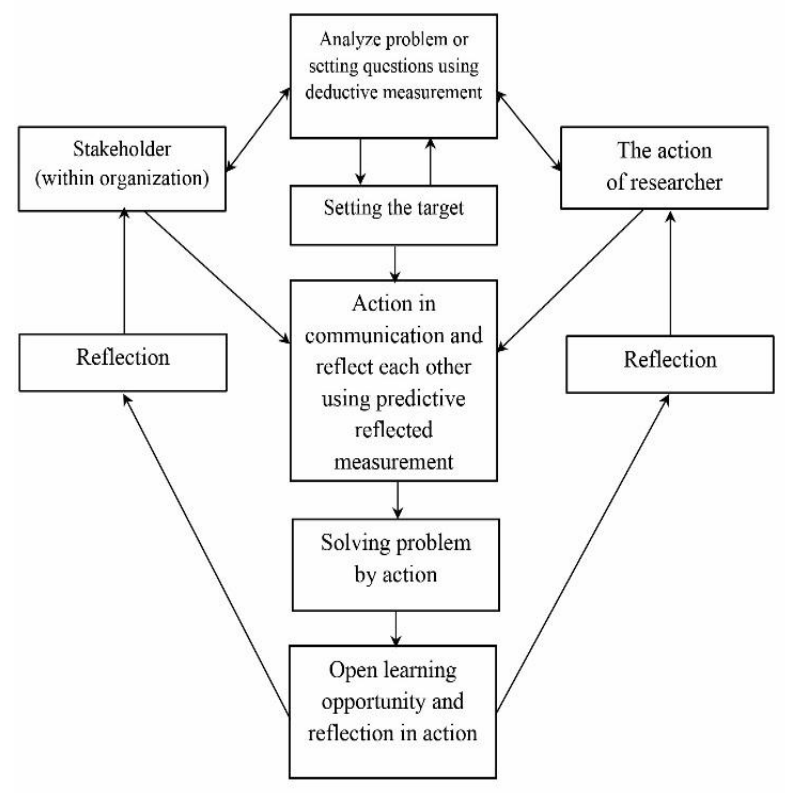

Fig.2 Action Research Design Model for Lesson learned

Sources: Adjusted from Greenwood and Levin (2007) [6] This research has set a research process by dividing the study into 3 phases: Phase 1, Documentation study, and Field Study, Phase 2, Participatory Action Research (PAR) and Phase 3 Validate the innovative prototype model from the group who involved in the Management of the Coronavirus Outbreak Situation 2019 (COVID-19) and was shown in Fig.3 as follows. 


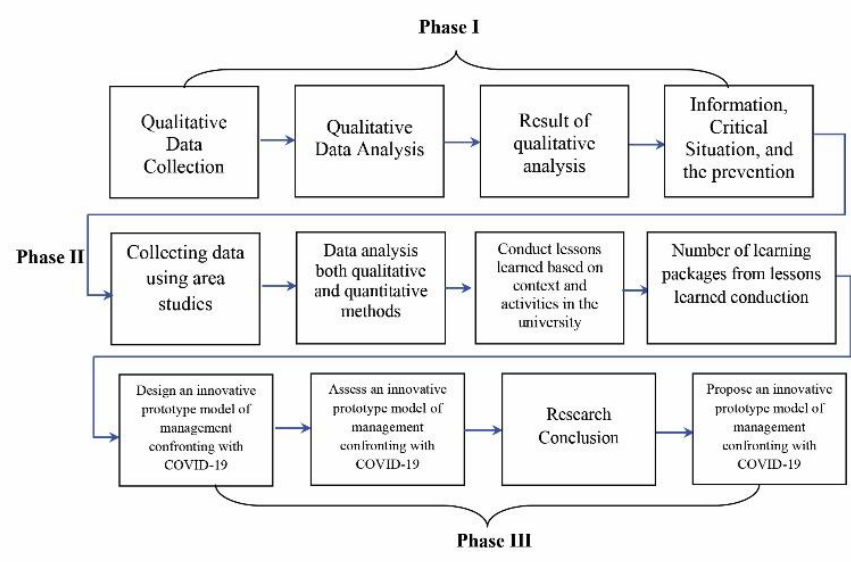

Fig. 3 Research procedures for innovative models confronting with COVID-19

The findings of this study are drawn from the lessons learned from the urgent situations, which are urgently conducted and the results are adapted in a timely manner during the epidemic situation of Coronavirus 2019 (COVID-19).

\section{Research Results}

Research results were divided into 3 areas according to the research objectives as follows:

1) Crisis analysis results, the situation and measures to prevent the spread of the coronavirus 2019 (COVID-19) found that the outbreak of the coronavirus 2019 affects the university administration that was unable to operate normally. This pathogen has never been seen before in humans, it causes respiratory illness in humans and can be transmitted from person to person. Common symptoms include respiratory symptoms, fever, cough, shortness of breath, difficulty breathing in very severe cases. It can lead to complications such as pneumonia, kidney failure, or possibly death. Palliative treatment is currently used to alleviate various ailments as there is no vaccine yet. For disease prevention measures of Mahachulalongkorn rajavidyalaya University, 5 measures were established, which are 1) measures for the performance of university personnel to enable personnel from all areas of work to work from home and organize an agenda for changing the day to work for personnel; 2) measures for educational management, the university has set up a study in online teaching and assessment test for all courses and all levels of educational management; 3 ) measures for staff and students living in Mahachulalongkornrajavidyalaya University, the university issued intensive supervision measures, 4) measures for public communication as a university institute and a Sangha university, and 5) a measure of internal management within the Mahachulalongkornrajavidyalaya University area. All five measures will be carried out with the university's center for the control and prevention of the epidemic of COVID 19.

2) The results of conducting lessons learned on management of the coronavirus epidemic situation (COVID-19) of Mahachulalongkornrajavidyalaya University found that the university has implemented a good practice (Best Practice). The six areas consisted of the first prototype was health care prototype for university students and staff; the second prototype was model of teaching and learning with Multi-Online
Communication Prototype; the third prototype was a model for research and academic management online using online service prototype; the fourth prototype was sharing prototype: the fifth prototype was a model of public communication, Dharma for creating morale to be mindful and patient during difficult situations as Dhamma talk therapy prototype; and the sixth prototype was model of COVID-19 management with the establishment of Center for Control and Prevention of COVID 19 as COVID-19 Management Prototype. Model of Best Practices as the part of the main prototype model was developed and was shown as in Fig.4.

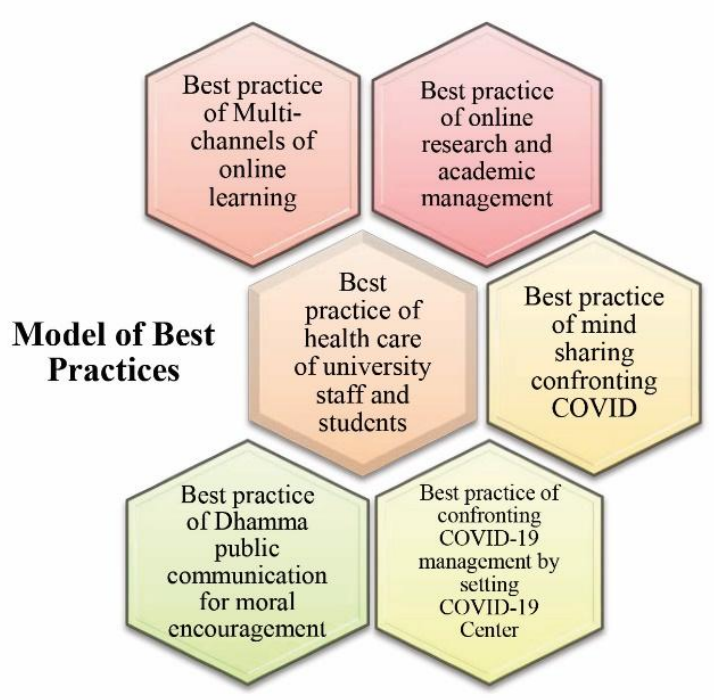

Fig. 4 Model of Best Practices

3) An innovative prototype model of management to confront with Coronavirus Disease 2019 (COVID-19): A case study of Mahachulalongkornrajavidyalaya University is a model of proposing the phenomenon occurring in Mahachulalongkornrajavidyalaya University according to the new normal life. There are 7 adaptations that include 1) method of new normal life focusing on health care, 2) method of new normal working using online communication, 3) method of new normal teaching and instruction using online blended learning, 4) method of new normal research and academic management focusing on online working, 5) method of Dhamma public communication in new normal focusing on social distancing, 6) method of sharing expression in new normal using sharing pantries, and 7) method of coexistence in university following Buddhist new normal. Model of Seven ways of New Normal Confronting with COVID-19 was shown in Fig.5. 


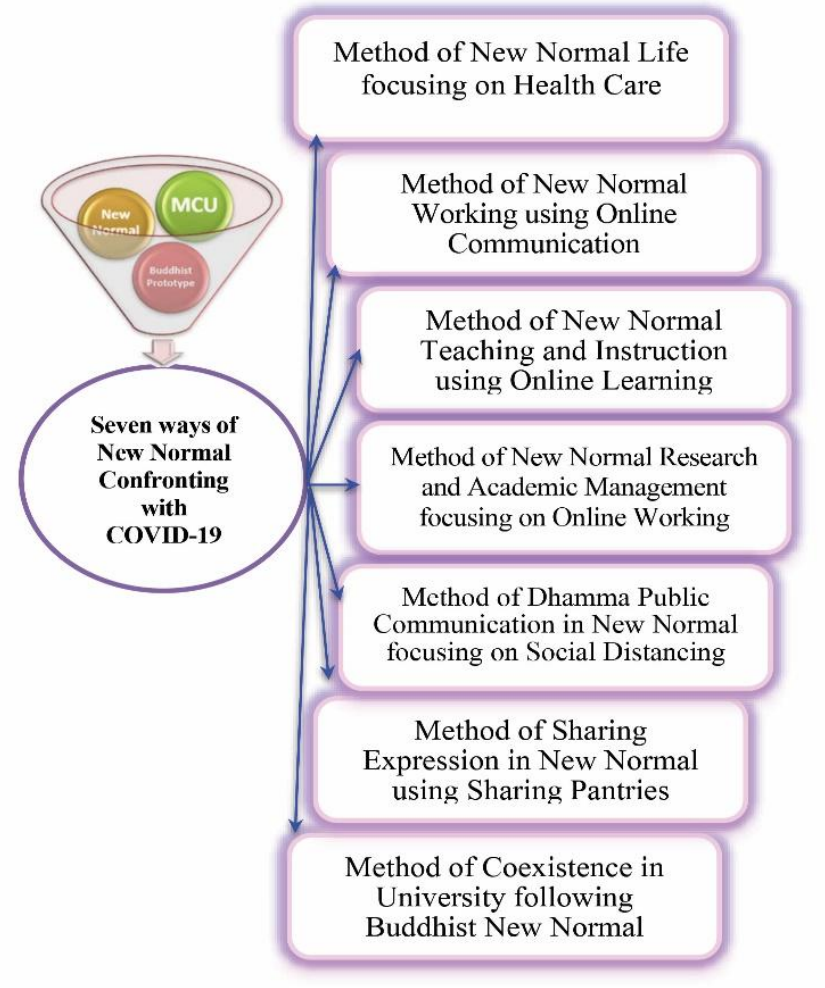

Fig. 5 Seven ways of New Normal Confronting with COVID19

\section{Research Reflection}

There are many studies on the situation of the global COVID outbreak including Thailand was affected by the situation cause education about the concept of many measures as evidenced in research and studies, such as the coronavirus (COVID-19) outbreak in Thailand (Surachai Chokchanchitchai, 2020), public opinion on the prevention and treatment of COVID-19. According to the principle of the four Noble truth (Phrakhru Sripariyatwithan (Phramaha Man Kupaatarangsi / Thongwijit), 2020) [7] Cloud MeetingTelemedicine with medical personnel in the COVID-19 era (Teeraphat Adulyatham, 2020) [8], Buddhist methods for self-care in the COVID-19 situation (Naphaphat Ngambussabongsopin, 2020) [9].

The research or results of the study as a whole will focus on living in normal situations, preventive and corrective measures to the problems that arise under the concept seen as a problem (Dukkha) that needs to be studied for the cause. Possibility causes that come (Samudaya) and lead to seeking measures or guidelines to lead to a solution or the cause of the COVID that occurs (Magga) until it hopes to work, or need the results of measures (Nirodha) that will lead to the correction and prevention of the cause that has happened as it will lead to the systematic development and the systematic correction as well.

From the presentation of research reflections on "An innovative prototype model of management confronting with Coronavirus Epidemic Situation 2019 (COVID-19): A Case Study of Mahachulalongkornrajavidyalaya University", it reflects what has been received from lessons learned from local management under the epidemic situation of COVID-19. It is a reflection of the research results that are being carried out urgently in order to immediately apply the findings, to design an action research to find answers to an immediate event where the lesson results were presented as a prototype model for the novel coronavirus outbreak.

For the body of knowledge from research indicated that An innovative prototype model of management to confront with Coronavirus Disease 2019 (COVID-19): A case study of Mahachulalongkornrajavidyalaya University was a lessons learned on management of the fight against the coronavirus epidemic situation 2019, a phenomenon that occurred in Mahachulalongkornrajavidyalaya University according to the New Normal way, resulting in a model of management adaptation confronting with the epidemic situation of the Coronavirus 2019 (COVID-19), known as "Seven ways of New Normal Confronting with COVID-19", which is an innovative prototype model from this research [10], and can be shown as below figure.

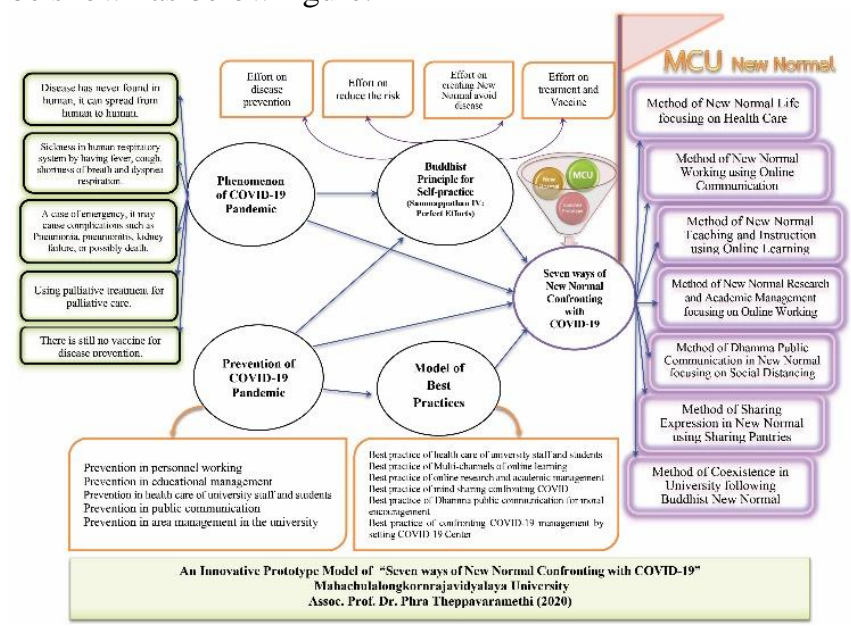

Fig. 6 MCU Innovative Prototype Model Confronting with COVID-19

\section{Recommendations}

\section{A. Recommendations for applying research results}

1) The results of research on the situation of the coronavirus outbreak 2019 (COVID-19) found that there is no vaccine yet, so personnel and students should follow the measures set by the university including acting according to the national guidelines regarding the declaration of emergency situations in accordance with the Emergency Decree on Public Administration in Emergency Situations for the benefit of taking care of the health of themselves and those around them in the future.

2) From a lessons learned, it found that the university has implemented best practice of a model for personnel and students of Mahachulalongkornrajavidyalaya University during the coronavirus outbreak situation 2019, there should be supervision to adhere to continually in order to prevent the spread of the epidemic from occurring for both university personnel and students including the area of the university.

3) Result of innovative prototype models "Seven ways of New Normal Confronting with COVID-19" of Mahachulalongkornrajavidyalaya University. This showed a concrete model of practice under management during the COVID-19 epidemic situation. This innovative prototype 
model should be published to all university departments, including campuses, monastic colleges, and resource unit across the country to guide the implementation of the organization's context, respectively.

\section{B. Recommendations for the next research}

1) The findings obtained from this research are derived from Action Research that designed research to solve problems during urgent situations. The obtained research results can be used to design participatory action research (PAR) by using a research model based on the new normal by operating with online social distance.

2) A quantitative research in the nature of a causal relationship model should be designed to examine the innovative model of the coronavirus epidemic management (COVID-19) model of Mahachulalongkornrajavidyalaya University by setting educational areas across the country in order to obtain empirical information including the determination of Buddhist variables in the model to study the influence of variables on the effectiveness of COVID-19 management.

3) Design-Based Research (DBR) should be conducted to develop the continuity of an innovative prototype model for management of the coronavirus epidemic situation 2019 (COVID-19) of Mahachulalongkornrajavidyalaya University obtained from this research. It is a formative research that focuses on the use of research results that focus on the design that meets the needs of the users. The findings are linked to research utilization and to create innovative invention that caused by the research obtained.

\section{Conclusion}

This summary is written from the research on "An innovative prototype model of management to confront with Coronavirus Disease 2019 (COVID-19): A case study of Mahachulalongkornrajavidyalaya University". Action research was conducted and the research process was divided into 4 important steps: Step 1 Planning (Plan), Step 2 Action (Act), Step 3 Observe and Step 4 Reflect the results (Reflect) or called that PAOR process. The issues for data collection were 1) the COVID-19 crisis, 2) the COVID19 epidemic situation, 3) surveillance and prevention, 4) critical risk management, and 5) the innovative prototype model for management of the COVID-19 epidemic situation, the period of study was the emergency declaration period due to the situation of the coronavirus 2019 (COVID19) epidemic. An innovative prototype model of Seven ways of New Normal Confronting with COVID-19, there are 7 ways consisted of 1) method of new normal life focusing on health care, 2) method of new normal working using online communication, 3) method of new normal teaching and instruction using online blended learning, 4) method of new normal research and academic management focusing on online working, 5) method of Dhamma public communication in new normal focusing on social distancing, 6) method of sharing expression in new normal using sharing pantries, and 7) method of coexistence in university following Buddhist new normal. This book presents knowledge from research showing innovative prototype model derived from lessons learned on management to confronting the epidemic situation of the coronavirus 2019, a phenomenon occurring in Mahachulalongkornrajavidyalaya University according to the new normal resulting in a model of adaptation in the management of the coronavirus epidemic situation 2019 (COVID-19).

\section{References}

[1] Shan-Lu Liu and Linda Saif. (2020). Emerging Viruses without Borders: The Wuhan Coronavirus. Retrieved on 15 March 2020, from https://www.researchgate.net/publication/ 338760577

[2] Peng Shao. (2020). Impact of city and residential unit lockdowns on prevention and control of COVID-19. Retrieved on 18 March 2020, from https://www.researchgate.net/ publication/340000607

[3] European Centre for Disease Prevention and Control. (2020). Novel coronavirus disease 2019 (COVID-19) pandemic: increased transmission in the EU/EEA and the UK - sixth update - 12 March 2020. Stockholm: ECDC; 2020.

[4] Shulin Liu, Zhi-gang Wang (Nankai University), Hai-Yan Xie, An-An Liu. Single-Virus Tracking: From Imaging Methodologies to Virological Applications. Chemical Reviews. 120(3), January 2020, DOI: 10.1021/acs. chemrev.9b00692

[5] Hui Luo, Qiao-ling Tang, Ya-xi Shang, Jian-Ping Liu. (2020) . Can Chinese Medicine Be Used for Prevention of Corona Virus Disease 2019 (COVID-19)? A Review of Historical Classics, Research Evidence and Current Prevention Programs. Chinese Journal of Integrative Medicine• February 2020, From https://www.researchgate.net/ publication/339312841

[6] D.J.Greenwood and M. Levin, Introduction to Action Research, 2nd Edition, SAGE Publishing, 2007. DOI: https://dx.doi.org/10.4135/9781412984614

[7] Phrakhru Sripariyatwithan (Phramaha Man Kupaatarangsi/ Thongwijit), Opinion of people toward the prevention of Corona 
Virus Disease 2019 following the four noble truths, Journal of Art Management, 4(3), September - December 2020: 521536.

[8] T. Adulyatham, Cloud meetingTelemedicine with medical staff in COVID-19 pandemic, Journal of The Department of Medical Services, 45(2), April - June 2020, 5-7.

[9] N. Ngambussabongsopin, Buddhist method for self-reliance during COVID-19 situation, Journal of Graduate Studeis Review, 16(2), May-August, 2020: 42-58.

[10] Phra Theppavaramethi, and others, MCU Innovative Prototype Model Confronting with COVID-19, Ayutthaya: Mahachulalongkornrajavidyalaya Printing Press, 2020. 